\title{
Current considerations in direct percutaneous endoscopic jejunostomy
}

\author{
Yanfei Zhu PhD, Liping Shi MSc, Hao Tang BM, Guoqing Tao BM
}

Y Zhu, L Shi, H Tang, G Tao. Current considerations in direct percutaneous endoscopic jejunostomy. Can J Gastroenterol 2012;26(2):92-96.

BACKGROUND: Direct percutaneous endoscopic jejunostomy (DPEJ) is a well-known approach to deliver postpyloric enteral nutritional support to individuals who cannot tolerate gastric feeding. However, it is technically difficult, and some case series have reported significant procedural failure rates. The present article describes current indications, successes and complications of DPEJ placement METHODS: A MEDLINE database search was performed to identify relevant articles using the key words "direct percutaneous endoscopic jejunostomy", "percutaneous endoscopic gastrostomy", and "percutaneous endoscopic gastrostomy with a jejunal extension tube". Additional articles were identified by a manual search of the references cited in the key articles obtained in the primary search.

RESULTS: DPEJ is gradually becoming more common in the treatment of patients who cannot tolerate gastric feeding. Differences in patient selection and technique modifications may contribute to the various success rates reported. Failure is most often due to inadequate transillumination or gastroduodenal obstruction. Currently, there are limited data to evaluate the safety and effectiveness of DPEJ.

CONCLUSION: The clinical use of DPEJ is increasing. With appropriate care and expertise, DPEJ may prove to be reliable and safe.

Key Words: Adverse events; Application; Direct percutaneous endoscopic jejunostomy; Percutaneous endoscopic gastrostomy

$\mathrm{C}$ nteral feeding via a percutaneous approach using endoscopy is a

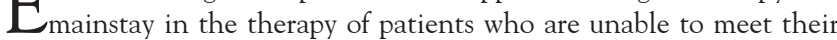
nutritional needs orally. Percutaneous endoscopic gastrostomy (PEG) is a well-known, safe and effective modality for enteral feeding in patients with oropharyngeal dysphagia or malignant upper gastrointestinal (GI) obstruction (1-3). However, it may not be a viable option in patients with severe gastroparesis or gastric outlet obstruction. Large gastric tumours or previous gastric resection render this procedure technically difficult. This has led to the development of enteral feeding methods that enable tube placement distal to the ligament of Treitz (4-6).

There are multiple options for gaining long-term access for postpyloric enteral nutrition including PEG with a jejunal extension tube (PEGJ), direct percutaneous endoscopic jejunostomy (DPEJ), open and laparoscopic surgical jejunostomies (SJ) and direct jejunal catheter placement by interventional radiologists. PEGJ is the most commonly performed nonsurgical method of accessing the jejunum. Unfortunately, this indirect method is becoming unpopular due to technical difficulty at the time of placement and other problems including clogging and migration into the stomach, which often necessitates reintervention $(7,8)$. DPEJ was first described by Shike et al (9) in 1987, and has gained popularity among gastroenterologists as an enteral access method. It

\section{Les considérations actuelles en matière de jéjunostomie endoscopique percutanée}

HISTORIQUE : La jéjunostomie endoscopique percutanée directe (JEPD) est une approche bien connue pour administrer une alimentation de soutien entérique post-pylorique aux personnes qui ne peuvent tolérer une alimentation gastrique. Elle est toutefois difficile sur le plan technique, et certaines séries de cas ont fait état d'un taux d'échecs de l'intervention. Le présent article décrit les indications actuelles, les réussites et les complications de l'installation d'une JEPD.

MÉTHODOLOGIE : Les chercheurs ont effectué une recherche dans la base de données MEDLINE afin de repérer les articles pertinents grâce aux mots clés direct percutaneous endoscopic jejunostomy, percutaneous endoscopic gastrostomy et percutaneous endoscopic gastrostomy with a jejunal extension tube. Ils ont trouvé d'autres articles au moyen d'une recherche manuelle des références citées dans les principaux articles obtenus lors de la première recherche.

RÉSULTATS : La JEPD devient graduellement plus courante pour le traitement des patients qui ne peuvent tolérer l'alimentation gastrique. Les différences dans la sélection des patients et les modifications des techniques peuvent contribuer aux divers taux de succès déclarés. L'échec est surtout causé par une transillumination inadéquate ou une obstruction gastroduodénale. Pour l'instant, les données permettant d'évaluer l'innocuité et l'efficacité de la JEPD sont limitées.

CONCLUSION : L'utilisation clinique de la JEPD augmente. Grâce à des soins et des compétences pertinentes, elle pourrait se révéler fiable et sécuritaire.

involves the insertion of a feeding tube directly into the jejunum under endoscopic guidance. Compared with PEGJ, the larger-bore DPEJ tubes clog less, kink less and do not migrate, leading to a significant reduction in the need for endoscopic troubleshooting. SJ can be performed with either open or laparoscopic techniques, with success rates approaching $100 \%$. However, this method requires general anesthesia, which could lead to more severe complications. Unlike SJ, DPEJ placement does not require general anesthesia, and requires only a single small incision in the abdominal wall. Hence, DPEJ appears to be the preferred mode of enteral access, and its clinical use is increasing. However, compared with PEG or PEGJ, DPEJ is more difficult and is associated with higher procedural failure rates $(10,11)$. Furthermore, only limited research involving DPEJ has been reported. In the present article, we review the current issues to consider in the clinical application of DPEJ and evaluate the safety of DPEJ placement.

\section{INDICATIONS FOR AND CONTRAINDICATIONS TO DPEJ}

Patients are recommended for DPEJ as the primary means of artificial nutritional support if they are unable to maintain nutrition orally, and if conventional endoscopic gastrostomy insertion is inappropriate (because of gastric malignancy, resection or dysmotility). Appropriate

Department of General Surgery, Wuxi People's Hospital of Nanjing Medical University, Jiangsu, China

Correspondence: Dr Yanfei Zhu, Department of General Surgery, Wuxi People's Hospital of Nanjing Medical University, No. 299, Qingyang Road,

Wuxi 214023, Jiangsu Province, China. Telepnone 86-510-85350091, fax 86-510-82828435, e-mail zhuyanfei_2002@163.com

Received for publication November 3, 2010. Accepted June 23, 2011 
indications for and contraindications to DPEJ include patients who require prolonged enteral feeding and who meet the criteria summarized in Table 1. DPEJ is commonly used in patients with nonfunctional stomachs (diabetic gastroparesis) who cannot tolerate gastric feedings, patients with surgically altered upper gut anatomy that precludes PEG (eg, esophagectomy or gastrectomy), in patients experiencing or at risk for aspiration because of gastroesophageal reflux, and in patients with esophageal carcinoma and dysphagia undergoing preoperative chemoradiation. Moreover, DPEJ may also play a role in the nutritional support of some patients with severe acute or chronic pancreatitis (CP) (12-14).

\section{DPEJ PROCEDURE}

DPEJ placement is performed according to the technique described by Shike et al (9) and Shike and Latkany (15), with some modifications. Before the procedure, all patients should provide documented consent and have normal coagulation parameters. Variations in technique include the type of endoscope and PEG kits used, usage (or otherwise) of fluoroscopy and/or transillumination, and type of needle used for entry into the gut lumen. The choice of endoscope depends on whether previous upper GI surgery has been performed. If the upper GI tract is intact, an enteroscope is usually selected, with shorter endoscopes used if part of the upper GI tract has been resected or anastomosed.

The endoscope is advanced into the jejunum to create a discrete area of transillumination visible on the external surface of the abdominal wall. The ideal site for tube insertion is further confirmed by applying external pressure with a finger to create an intrajejunal indentation. Following a standard skin preparation and application of a local anesthetic, a trocar or drainage access needle is advanced alongside or in place of the needle. The trocar is then passed percutaneously alongside the finder needle in the same trajectory. When the trocar is visible endoscopically, the finder needle is released from the snare and the trocar is endoscopically grasped with the snare. The remainder of the examination proceeds as it does with PEG placement, as the loop is passed through the trocar and the endoscope is withdrawn. Finally, the endoscope is reinserted to confirm proper tube positioning, when possible. PEG should be implemented immediately after DPEJ if a patient with severe gastroparesis requires both gastric decompression and jejunal feeding $(16,17)$.

Schematic illustrations of PEG, PEGJ and DPEJ are presented in Figure 1 to facilitate understanding. The tube calibre commonly used in PEG exceeds $20 \mathrm{Fr}$, while the calibre of the jejunal tube in DPEJ is often larger than $15 \mathrm{Fr}$. Currently, there are no unified criteria to limit the size of tube used in PEG or DPEJ, and some small-calibre gastric tubes could also be safely used in DPEJ.
TABLE 1

Indications for and contraindications to direct percutaneous endoscopic jejunostomy

\begin{tabular}{|c|c|}
\hline Indication & Contraindication \\
\hline Gastric dysmotility & Uncorrected coagulopathy \\
\hline Gastric outlet obstruction & Large-volume ascites \\
\hline High risk for aspiration & Intra-abdominal perforation \\
\hline Post upper gastrointestinal operation & Severe cachexia, intolerance \\
\hline \multicolumn{2}{|l|}{$\begin{array}{l}\text { Esophageal or gastric malignancy } \\
\text { (incurable or recurrence) }\end{array}$} \\
\hline Pancreatitis & \\
\hline
\end{tabular}

\section{APPLICATION OF DPEJ IN GI DISORDERS}

Enteral nutrition is the goal of therapy for most patients who require nutritional support and, in severely ill patients with a functional gut, it can be used safely. A percutaneous approach to jejunal feeding should be considered among the options for nutritional support $(18,19)$. Due to the lack of interference when used in the upper GI and larger tube calibre, DPEJ has been recommended for patients with gastric malignancy, dysmotility and those who have undergone resection $(20,22)$. Postpyloric feeding reduces the rates of aspiration pneumonia, gastroesophageal regurgitation, septic complications, multiple organ failure and length of hospitalization. DPEJ is physiologically advantageous because of less disturbance to normal hormone secretion patterns of the gut, its ability to provide a complete nutritional mixture, including fibre, and is associated with a lower overall cost $(23,24)$.

Referrals for DPEJ have increased recently, largely as a result of its reliability for enteral access compared with PEG or PEGJ (16,25-27). However, comparative data for DPEJ versus PEGJ feeding are scarce. For long-term stable jejunal access, DPEJ appears to be superior to PEGJ. The patency rate is greater and the need for endoscopic reintervention is significantly less because DPEJ has a stable anchor within the small bowel and larger-calibre tube compared with PEGJ. However, the difficulty of the technique and the need for additional PEG for gastric decompression are the main disadvantages. The comparison between DPEJ and PEGJ is further emphasized in Table 2. Fan et al (11) retrospectively compared complications and the need for endoscopic reintervention to maintain jejunal access in patients with DPEJ versus PEGJ at a single institution. Fifty-six patients with DPEJ and 49 with PEGJ were enrolled in their study. After a six-month follow-up period, feeding tube patency was significantly higher and there were fewer complications in the DPEJ group. Additonal randomized control trials are needed to compare the safety and efficacy between the two techniques.

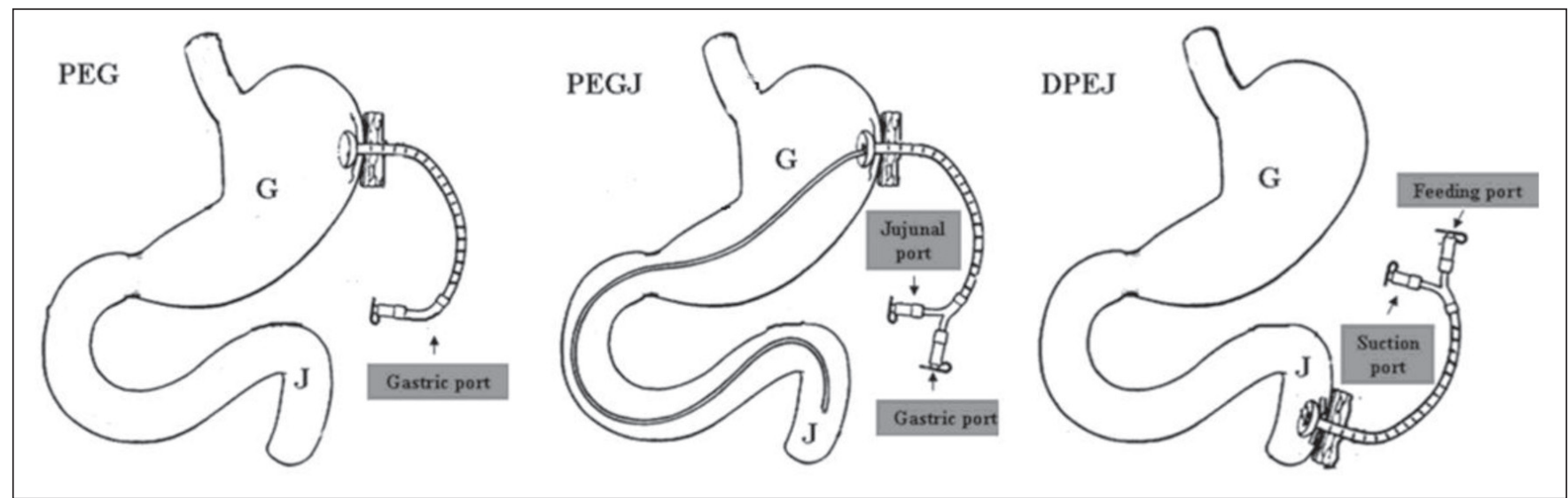

Figure 1) Schematic illustrations of percutaneous endoscopic gastrostomy (PEG, left) in which the gastric $(G)$ feeding tube is inserted directly into the stomach; PEG with a jejunal (J) extension tube (PEGJ, middle) in which the intraluminal bumper of the PEG tube contains a suction port to facilitate G decompression. The jejunal feeding port should be placed distal to the ligament of Treitz; Direct percutaneous endoscopic jejunostomy (DPEJ, right) in which the J feeding tube is inserted directly into the small bowel distal to the ligament of Treitz. 


\section{APPLICATION OF DPEJ IN PATIENTS WITH CP}

The goals of management in patients with CP are to minimally stimulate the exocrine pancreas and to provide optimal nutritional support. Oral or gastric feeding markedly increase pancreatic secretion by stimulation of the cephalic, gastric and intestinal phases of exocrine pancreatic secretion. In contrast, jejunal infusion is associated with either no increase or insignificant increases in volume, bicarbonate and protein content in most canine and human studies. Prolonged jejunal access in CP is best maintained by placement of DPEJ. If jejunal feeding access was not attained at the time of surgical intervention for pancreatitis, DPEJ can be placed and used during the recovery period. DPEJ can also be used when malnutrition occurs due to limitation of oral intake because of pain or intolerance to exogenous pancreatic enzymes, elemental formulas or medium-chain triglycerides. Advances in techniques and equipment have made DPEJ placement efficient and technically successful, with low morbidity (28). Prolonged enteral feeding with DPEJ may be beneficial in the management of pain, malnutrition and other complications of CP. Contraindications to DPEJ use in patients with CP are few. However, only a few isolated reports have been published. Nathanson et al (29) reported successful DPEJ placement in one patient with pancreatitis complicated by pseudocyst, with no severe complications. Hence, enteral feeding through a DPEJ is an appropriate initial means of nutritional support in the management of patients with CP. Additonal studies are needed to better define success rates, complications and outcomes of DPEJ in the management of patients with CP.

\section{APPLICATION OF DPEJ IN OBESE PATIENTS}

DPEJ is increasingly used as a method for obtaining jejunal enteral access. Identification of factors affecting the success and complication rates of DPEJ has been limited. Failures are most often attributed to inadequate transillumination or the inability to intubate the jejunum because of gastric outlet obstruction or proximal small-bowel obstruction, which may be related to obesity (30). Currently, no multicentre data evaluating DPEJ placement success and adverse events (AEs) in overweight and obese patients have been available. Maple (31) reported a DPEJ placement success rate $<40 \%$ in patients with an abdominal wall thickness exceeding $3 \mathrm{~cm}$ on abdominal computed tomography, a significantly worse placement rate than seen in patients with less abdominal wall fat. Mackenzie et al (32) first compared the success rate and AEs associated with DPEJ placement in patients who were overweight and patients who were obese compared with patients who were normal or underweight defined by body mass index (BMI). In their retrospective database review of $80 \mathrm{DPEJ}$ placements, success rates of patients were $96 \%$ for underweight, $81 \%$ for normal weight, $73 \%$ for overweight and $60 \%$ for obese. They considered that DPEJ placement in patients who were overweight or obese was feasible, but procedural success was less frequent, and a trend toward more frequent major AEs was seen than in persons with normal or decreased BMI. BMI was an easily assessed preprocedural factor for DPEJ success and complication rates. These findings lend support to previous observations reported by Maple et al (30). However, with regard to attaininig enteral access, infectious wound complications and nosocomial infections are more frequent, and hospital length of stay was longer in obese patients undergoing abdominal surgery compared with nonobese controls. Four of the five severe AEs occurred in patients with a BMI $>25 \mathrm{~kg} / \mathrm{m}^{2}$ in the study by Mackenzie et al (32). Additonal studies to evaluate the long-term safety and complications of DEPJ placement in obese patients should be performed.

\section{APPLICATION OF DPEJ IN PEDIATRIC PATIENTS}

DPEJ is a valuable method of delivering postpyloric enteral nutritional support to patients who cannot tolerate gastric feeding. The safety and efficacy of DPEJ in adults has previously been reported $(10,16)$. However, reports on the use of DPEJ in pediatric patients are rare. Five pediatric patients with severe gastric motility problems and intolerance to gastric feeding characterized by regurgitation and

\section{TABLE 2}

Comparison of PEGJ and DPEJ

\begin{tabular}{lll}
\hline Characteristic & PEGJ & DPEJ \\
\hline Calibre of jejunal tube & $\leq 10 \mathrm{Fr}$ & $\geq 15 \mathrm{Fr}$ \\
$\begin{array}{l}\text { Technical difficulty } \\
\text { Complications }\end{array}$ & Normal & Difficult \\
Tube clogging or migration & & \\
Enterocutaneous fistula & Common & Few \\
Other nontube complications & Few & Common \\
\hline
\end{tabular}

DPEJ Direct percutaneous endoscopic jejunostomy; PEGJ Percutaneous endoscopic gastrostomy with a jejunal extension tube

aspiration of food contents, who underwent DPEJ placement between January 2000 and January 2003, and had available follow-up data were enrolled in a study by Virnig et al (33). All five attempted DPEJs were placed successfully, with two minor complications of peristomal leakage and peristomal skin infection. One DPEJ was replaced two years after placement because of fungal degradation. The mean weight gain among all patients was $10.3 \mathrm{~kg}$ in a mean of 22.6 months. No major complications occurred, and all patients gained weight after tube placement. The authors believed that DPEJ placement appeared to be a safe and effective approach to enteral nutritional support requiring long-term access to the jejunum in pediatric patients. Nevertheless, further study of DPEJ tubes in pediatric patients is necessary to evaluate complication rates and long-term effectiveness in this population.

\section{OUTCOMES OF DPEJ}

Published success rates for DPEJ placement range broadly from $68 \%$ to $100 \%$, despite these studies originating from a limited number of centres. The success rate was $100 \%$ in both Shetzline's study and Barrera's research $(22,34)$ (Table 3). The success rate for DPEJ placement in the largest published series $(n=286,68 \%$ success $)$ is lower than that reported in four other previous reports ( $72 \%$ to $100 \%)(10,11,16,21)$. Reasons for the differences in published outcomes may include technique with various modifications, patient selection bias among some smaller series and publication bias toward optimal outcomes in selected centres. Patients with cancers $(28 \%)$, gastroparesis $(21 \%)$, previous upper gastrointestinal surgery $(19 \%)$, at high risk for aspiration $(13 \%)$ and others $(19 \%)$ were enrolled in the largest study. DPEJ placement appeared to be more successful in patients who had undergone upper GI resection. Hence, it was reasonable that the success rate of DPEJ reported was partly proportional to the number of patients who underwent upper gut surgery.

Failures are most often attributed to inadequate transillumination or the inability to intubate the jejunum because of gastric outlet obstruction or proximal small-bowel obstruction (34,35). Even in failed cases, patients are exposed to the risks of anesthesia, exploratory percutaneous needle punctures and the cost burden of suboptimal resource use. Complications are more common in women and may be more common in procedures associated with an unsuccessful trocar pass. Skin site infections appear to be the most common minor complication. Other reported complications include enterocutaneous fistula, periprocedural hypotension and hypoxemia, moderate to severe site pain and pressure-induced jejunal ulcers (36-38). Maple et al (10) reported that $22.5 \%$ of all cases experinced AEs after DPEJ, and DPEJ was associated with a moderate or severe complication in approximately $10 \%$ of cases. Necrotizing fasciitis is recognized as a rare complication of PEG insertions, and first described after DPEJ by Chong and Delegge (39). The patient developed necrotizing fasciitis after DPEJ placement, which is characterized by fever, gas in the tissue and an obvious portal of entry. Computed tomography and magnetic resonance imaging may reveal gas within the affected tissue. Early and aggressive surgical intervention, antibiotics and supportive intensive care unit care must be commenced for patients to have any chance of survival. 
TABLE 3

Summary of direct percutaneous endoscopic jejunostomy application in recent case series

\begin{tabular}{|c|c|c|c|c|c|}
\hline Author (reference), year & Patients, n & Follow-up & Success rate, $\%$ & Complication(s) (n) & Re-interventions, $\mathbf{n}$ \\
\hline Rumalla and Baron (21), 2000 & 36 & 107 days & 72 & Enterocutaneous fistula (2) & 0 \\
\hline Shetzline et al (34), 2001 & 7 & 124 days & 100 & Abdominal pain (1) & 0 \\
\hline Barrera et al (22), 2001 & 17 & 28 months & 100 & Peritonitis (1) & 0 \\
\hline Fan et al (11), 2002 & 56 & 6 months & 72 & Enterocutaneous fistula (4) & 5 \\
\hline Maple et al (10), 2005 & 286 & 251 days & 68 & $\begin{array}{l}\text { Bowel perforations (7) } \\
\text { Major bleeds (3) } \\
\text { Aspiration (1) } \\
\text { Jejunal volvus (3) } \\
\text { Enterocutaneous fistula (20) } \\
\text { Site infection or site pain (47) }\end{array}$ & 3 \\
\hline Moran and Fisher (16), 2009 & 40 & 36 months & 97.5 & $\begin{array}{l}\text { Aspiration (2) } \\
\text { Peristomal leakage (2) }\end{array}$ & 0 \\
\hline
\end{tabular}

Identification of factors affecting the success and complication rates of DPEJ has been limited. Excellent transillumination is key to successful DPEJ placement, and successful placement has been shown by Maple et al (31) to be related to abdominal wall thickness. These authors believed that failed DPEJ attempts were associated with greater patient abdominal wall thickness, and that this should be taken into consideration before attempting DPEJ. Otherwise, review of existing abdominal images appears to have limited utility in predicting DPEJ outcome. To date, the cost effectiveness of artificial nutrition via DPEJ feeding in patients with advanced malignancy and limited life expectancy remains uncertain and deserving of further study (40). Therefore, it is important to select appropriate patients for the procedure to maximize success and minimize complication rates.

\section{REFERENCES}

1. Delegge MH. Percutaneous endoscopic gastrostomy.

Am J Gastroenterol 2007;102:2620-3.

2. Nicholson FB, Korman MG, Richardson MA. Percutaneous endoscopic gastrostomy: A review of indications, complications and outcome. J Gastroenterol Hepatol 2000;15:21-5.

3. Dharmarajan TS, Unnikrishnan D, Pitchumoni CS.

Percutaneous endoscopic gastrostomy and outcome in dementia. Am J Gastroenterol 2001;96:2556-63.

4. Thakore JN, Mustafa M, Suryaprasad S, Agrawal S. Percutaneous endoscopic gastrostomy associated gastric metastasis. J Clin Gastroenterol 2003;37:307-11.

5. Delegge RL, Delegge MH. Percutaneous endoscopic gastrostomy evaluation of device materials: Are we "failsafe". Nutr Clin Pract 2005;20:613-7.

6. Löser C, Aschl G, Hébuterne X, et al. ESPEN guidelines on artificial enteral nutrition - percutaneous endoscopic gastrostomy (PEG). Clin Nutr 2005;24:848-61.

7. Pearce CB, Duncan HD. Enteral feeding. Nasogastric, nasojejunal, percutaneous endoscopic gastrostomy, or jejunostomy: Its indications and limitations. Postgrad Med J 2002;78:198-204.

8. Zopf Y, Rabe C, Bruckmoser T, Maiss J, Hahn EG, Schwab D. Percutaneous endoscopic jejunostomy and jejunal extension tube through percutaneous endoscopic gastrostomy: A retrospective analysis of success, complications and outcome. Digestion 2009;79:92-7.

9. Shike M, Schroy P, Ritchie MA, Lightdale CJ, Morse R. Percutaneous endoscopic jejunostomy in cancer patients with previous gastric resection. Gastrointest Endosc 1987;33:372-4.

10. Maple JT, Petersen BT, Baron TH, Gostout CJ, Wong Kee Song LM, Buttar NS. Direct percutaneous endoscopic jejunostomy outcomes in 307 consecutive attempts. Am J Gastroenterol 2005;100:2681-8.

11. Fan AC, Baron TH, Rumalla A, Harewood GC. Comparison of direct percutaneous endoscopic jejunostomy and PEG with jejunal extension. Gastrointest Endosc 2002;56:890-4.

12. Baron TH. Direct percutaneous endoscopic jejunostomy. Am J Gastroenterol 2006;101:1407-9.

13. El Matary W. Percutaneous endoscopic gastrostomy in children. Can J Gastroenterol 2008;22:993-8.

\section{CONCLUSION}

DPEJ is a useful technique for gaining access to the jejunum for longterm nutritional support when gastric feeding is not appropriate or not possible. Careful selectivity of patients and advanced technique modifications may contribute to increasing success rates of DPEJ, and most complications seem nonfatal. However, patients and physicians should be aware of the risks involved. Additional research is needed to evaluate the long-term safety and effectiveness of DPEJ.

14. Baron TH. Direct percutaneous endoscopic jejunostomy through a mature gastrostomy tract. Gastrointest Endosc 2002;56:946-7.

15. Shike M, Latkany L. Direct percutaneous endoscopic jejunostomy. Gastrointest Endosc Clin N Am 1998;8:569-80.

16. Moran GW, Fisher NC. Direct percutaneous endoscopic jejunostomy high completion rates with selective use of a long drainage access needle. Diagn Ther Endosc 2009;2009:520879.

17. Luttmann A, Deppe H, Wejda BU, Huchzermeyer H, Dormann AJ. Placement of a jejunal enteral tube through a percutaneous endoscopic jejunostomy to prevent recurrent aspiration during intestinal feeding. Gastrointest Endosc 2005;61:492-3.

18. Bistrian BR. Parenteral vs. enteral nutrition? Crit Care Med 2008;36:3133.

19. Jeejeebhoy KN. Enteral nutrition versus parenteral nutrition the risks and benefits. Nat Clin Pract Gastroenterol Hepatol 2007;4:260-5.

20. Lien HC, Chang CS, Chen GH. Can percutaneous endoscopic jejunostomy prevent gastroesophageal reflux in patients with preexisting esophagitis? Am J Gastroenterol 2000;95:3439-43.

21. Rumalla A, Baron TH. Results of direct percutaneous endoscopic jejunostomy, an alternative method for providing jejunal feeding. Mayo Clin Proc 2000; 75:807-10.

22. Barrera R, Schattner M, Nygard S, et al. Outcome of direct percutaneous endoscopic jejunostomy tube placement for nutritional support in critically ill, mechanically ventilated patients. J Crit Care 2001;16:178-81.

23. Varadarajulu S, Delegge MH. Use of a 19-gauge injection needle as a guide for direct percutaneous endoscopic jejunostomy tube placement. Gastrointest Endosc 2003;57:942-5.

24. Buchman AL. Use of percutaneous endoscopic gastrostomy or percutaneous endoscopic jejunostomy in short bowel syndrome. Gastrointest Endosc Clin N Am 2007;17:787-94.

25. Frenz MB, van Heel D, Siuda G, Travis SP. Unusual malfunction of percutaneous endoscopic jejunostomy feeding tubes in patients with intestinal dysmotility. Endoscopy 2004;36:234-5.

26. Kakizoe S, Kakizoe Y, Kakizoe H, Matsuoka I, Kakizoe K. Ultrasound assisted percutaneous endoscopic jejunostomy. Hepatogastroenterology 2009;56:427-8. 
27. Sharma VK, Close T, Bynoe R, Vasudeva R. Ultrasound-assisted direct percutaneous endoscopic jejunostomy (DPEJ) tube placement. Surg Endosc 2000;14:203-4.

28. Fang JC, DiSario JA. Strategies in managing chronic pancreatitis placement of direct percutaneous endoscopic jejunostomy feeding tubes. Nutr Clin Pract 2004;19:50-5.

29. Nathanson A, Parrish C, Fang J, Yeaton P. A retrospective study of enterally fed adult patients with pancreatitis. Nutr Clin Pract 1999;14:100.

30. Maple JT, Petersen BT, Baron TH, Harewood GC, Johnson CD, Schmit GD. Abdominal CT as a predictor of outcome before attempted direct percutaneous endoscopic jejunostomy. Gastrointest Endosc 2006;63:424-30.

31. Maple JT. Direct percutaneous endoscopic jejunostomy in the obese: Proceed with caution. Gastrointest Endosc 2008;67:270-2.

32. Mackenzie SH, Haslem D, Hilden K, Thomas KL, Fang JC. Success rate of direct percutaneous endoscopic jejunostomy in patients who are obese. Gastrointest Endosc 2008;67:265-9.

33. Virnig DJ, Frech EJ, Delegge MH, Fang JC. Direct percutaneous endoscopic jejunostomy: A case series in pediatric patients. Gastrointest Endosc 2008;67:984-7.
34. Shetzline MA, Suhocki PV, Workman MJ. Direct percutaneous endoscopic jejunostomy with small bowel enteroscopy and fluoroscopy. Gastrointest Endosc 2001;53:633-8.

35. Jafri NS, Mahid SS, Minor KS, Idstein SR, Hornung CA, Galandiuk S. Meta-analysis: Antibiotic prophylaxis to prevent peristomal infection following percutaneous endoscopic gastrostomy. Aliment Pharmacol Ther 2007;25:647-56.

36. Schrag SP, Sharma R, Jaik NP, et al. Complications related to percutaneous endoscopic gastrostomy (PEG) tubes. A comprehensive clinical review. J Gastrointestin Liver Dis 2007;16:407-18

37. Ishii M, Teramoto S, Yakabe M, et al. Small intestinal intussusceptions caused by percutaneous endoscopic jejunostomy tube placement. J Am Geriatr Soc 2007;55:2093-4.

38. Hilal RE, Hilal T, Mushawahar A. Percutaneous endoscopic jejunostomy feeding tube knot working: A rare complication. Clin Gastroenterol Hepatol 2007;5:28.

39. Chong AK, Delegge MH. Necrotizing fasciitis after direct percutaneous endoscopic jejunostomy. Gastrointest Endosc 2005;61:912-3.

40. Shike M. Predicting the success of percutaneous endoscopic jejunostomy placement: The endoscope light outshines the CT scan. Gastrointest Endosc 2006;63:431-2. 


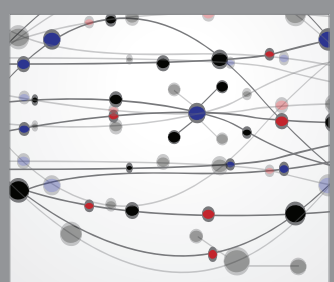

The Scientific World Journal
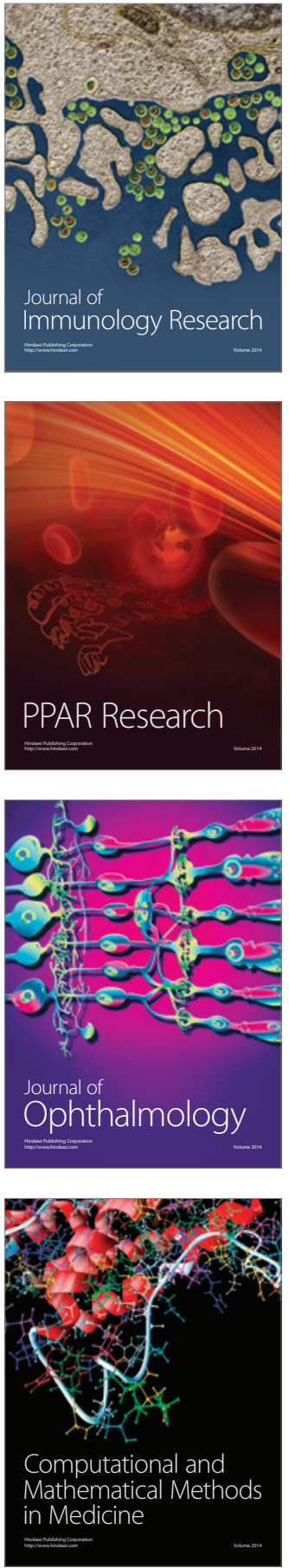

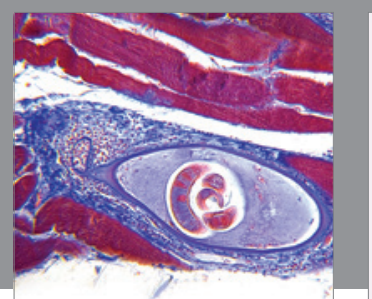

Gastroenterology Research and Practice

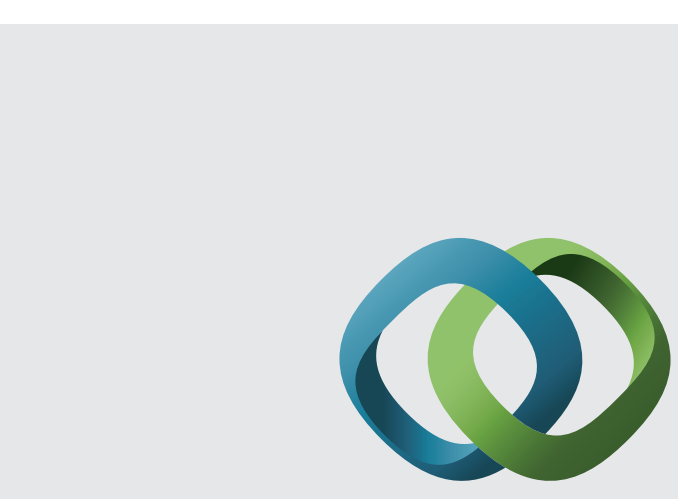

\section{Hindawi}

Submit your manuscripts at

http://www.hindawi.com
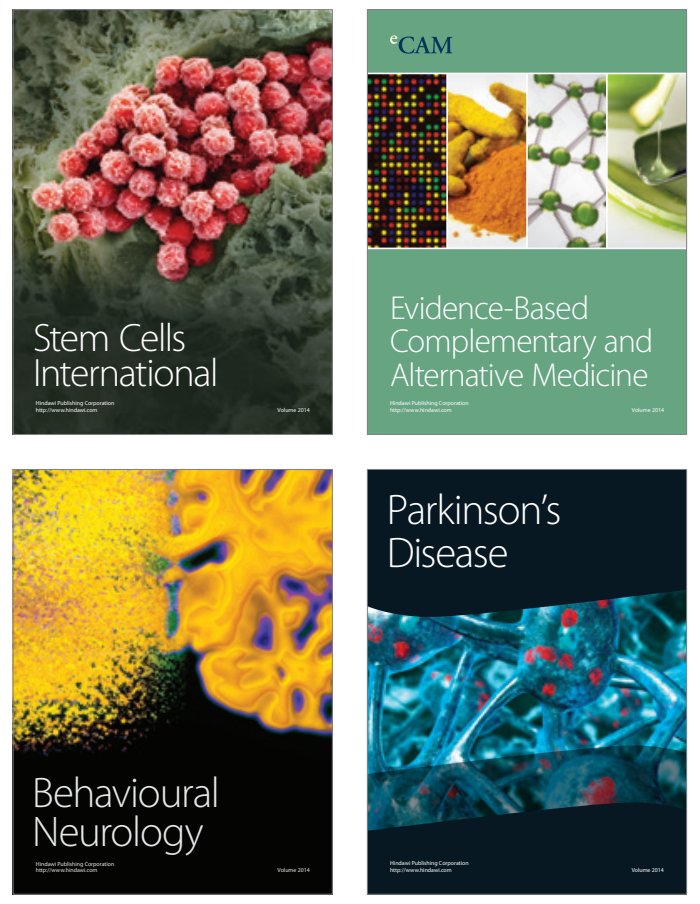
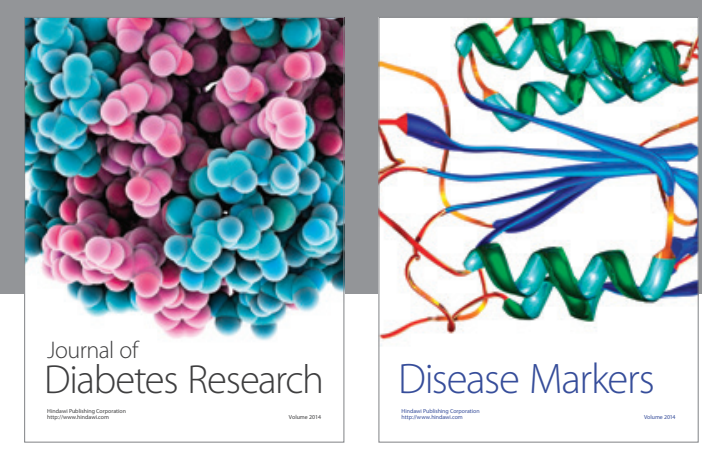

Disease Markers
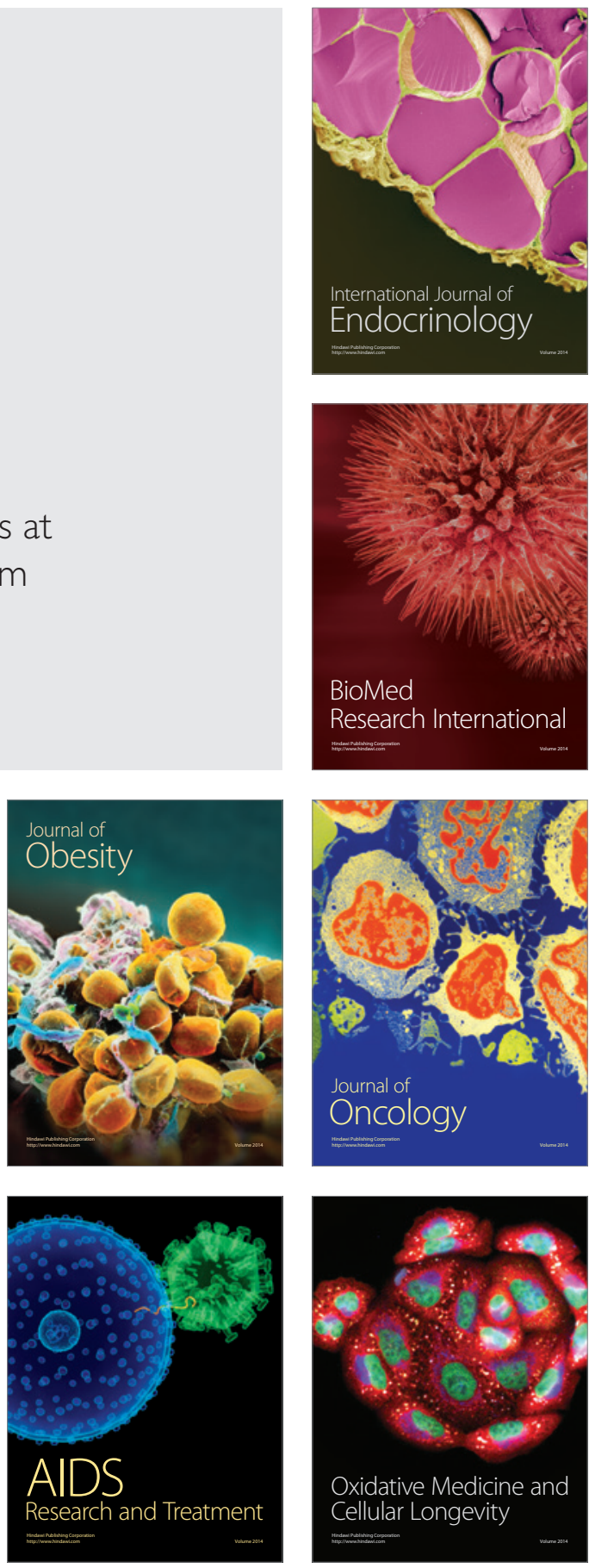